\title{
Ice nucleation in sulfuric acid/organic aerosols: implications for cirrus cloud formation
}

\author{
M. R. Beaver ${ }^{1}$, M. J. Elrod ${ }^{2}$, R. M. Garland ${ }^{1}$, and M. A. Tolbert ${ }^{1}$ \\ ${ }^{1}$ Department of Chemistry and Biochemistry and CIRES, University of Colorado, Boulder, Colorado, 80309, USA \\ ${ }^{2}$ Department of Chemistry and Biochemistry, Oberlin College, Oberlin, Ohio, 44074, USA
}

Received: 18 January 2006 - Published in Atmos. Chem. Phys. Discuss.: 28 March 2006

Revised: 21 June 2006 - Accepted: 1 August 2006 - Published: 4 August 2006

\begin{abstract}
Using an aerosol flow tube apparatus, we have studied the effects of aliphatic aldehydes $\left(\mathrm{C}_{3}\right.$ to $\left.\mathrm{C}_{10}\right)$ and ketones $\left(\mathrm{C}_{3}\right.$ and $\left.\mathrm{C}_{9}\right)$ on ice nucleation in sulfuric acid aerosols. Mixed aerosols were prepared by combining an organic vapor flow with a flow of sulfuric acid aerosols over a small mixing time ( $\sim 60 \mathrm{~s})$ at room temperature. No acid-catalyzed reactions were observed under these conditions, and physical uptake was responsible for the organic content of the sulfuric acid aerosols. In these experiments, aerosol organic content, determined by a Mie scattering analysis, was found to vary with the partial pressure of organic, the flow tube temperature, and the identity of the organic compound. The physical properties of the organic compounds (primarily the solubility and melting point) were found to play a dominant role in determining the inferred mode of nucleation (homogenous or heterogeneous) and the specific freezing temperatures observed. Overall, very soluble, low-melting organics, such as acetone and propanal, caused a decrease in aerosol ice nucleation temperatures when compared with aqueous sulfuric acid aerosol. In contrast, sulfuric acid particles exposed to organic compounds of eight carbons and greater, of much lower solubility and higher melting temperatures, nucleate ice at temperatures above aqueous sulfuric acid aerosols. Organic compounds of intermediate carbon chain length, $\mathrm{C}_{4}$ $\mathrm{C}_{7}$, (of intermediate solubility and melting temperatures) nucleated ice at the same temperature as aqueous sulfuric acid aerosols. Interpretations and implications of these results for cirrus cloud formation are discussed.
\end{abstract}

Correspondence to: $\mathrm{M}$. A. Tolbert

(margaret.tolbert@colorado.edu)

\section{Introduction}

Cirrus clouds, composed of water ice, form in the upper troposphere and are generally thought to have an overall warming effect at the Earth's surface. Since the occurrence of cirrus has increased beyond that attributable to aviation effects over the last few decades (Fahey and Schumann, 1999), changes in other anthropogenically produced aerosols could be another factor responsible for this increase. A more complete understanding of the critical factors involved in ice nucleation is needed to better model cirrus formation in the upper troposphere and its impact on climate. Sulfate aerosols, ubiquitous throughout the upper troposphere, are known to be important in the formation of cirrus clouds. Several laboratory studies, using a variety of techniques, have established homogeneous ice nucleation conditions for aqueous sulfuric acid and ammonium sulfate aerosols over the tropospherically relevant concentration range (0-50 wt\%) (Bertram et al., 1996; Bertram et al., 2000; Hung et al., 2002; Koop et al., 1998; Chen et al., 2000; Cziczo and Abbatt, 2001; Prenni et al., 2001b). There is much less data available for ice nucleation from other inorganic and organic species. However, based on physical data of melting and freezing temperatures of inorganic and organic compounds, Koop et al. (2000) have proposed a model which posits that aerosol water activity is the controlling factor in determining ice nucleation temperatures in the atmosphere.

It is currently known that organic compounds can constitute a significant mass fraction of individual upper tropospheric aerosols (Murphy et al., 1998). It has also recently been observed that atmospheric particles with high organic content are not as efficient at ice nucleation (DeMott et al., 2003; Cziczo et al., 2004). The effects that organic compounds have on the ability of particles to nucleate ice has only recently begun to be studied in the laboratory. Prenni et al. (2001a) found pure dicarboxylic acids were not

Published by Copernicus GmbH on behalf of the European Geosciences Union. 


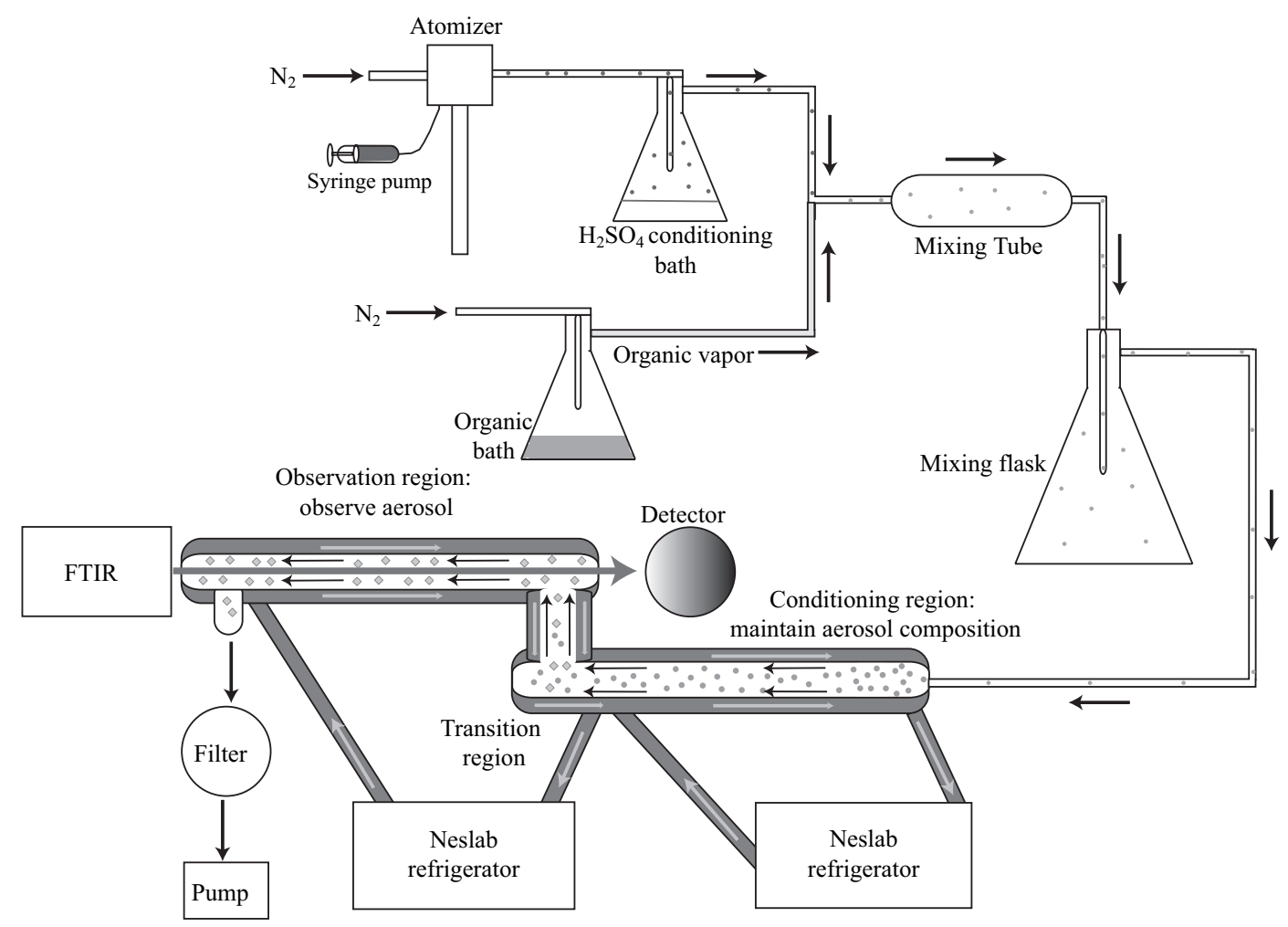

Fig. 1. Experimental setup for aerosol generation and measuring ice nucleation in mixed organic/sulfuric acid particles.

as efficient ice nuclei as sulfate particles of the same size. Wise et al. (2004) found that, in general, for internally mixed ammonium sulfate/dicarboxylic acid particles, the water activity of the aerosol could be used to predict ice nucleation conditions, in agreement with the Koop et al. (2000) model. A recent modeling study has investigated the role of dicarboxylic acids in atmospheric ice formation and found that changes in water uptake can affect the size of particles containing organics and thus can explain the observations that organic containing particles are less efficient at ice nucleation (Kärcher and Koop, 2005).

While ice nucleation has mainly been studied for mixtures of dicarboxylic acids with ammonium sulfate, other carbonyl-containing compounds, such as aldehydes and ketones, have been investigated at warmer temperatures to probe acid-catalyzed reactions with sulfuric acid (Iraci and Tolbert, 1997; Jang et al., 2002; Nozière and Riemer, 2003; Michelsen et al., 2004; Garland et al., 2006; Liggio et al., 2005; Nozière and Esteve, 2005; Zhao et al., 2005). An important characteristic of these acid-catalyzed reactions is the ability to form products of lower vapor pressure and solubility as well as higher melting points than the initial reactant compounds. The atmospheric presence of these carbonyl compounds is due to both primary emission from biogenic and anthropogenic sources, and from photo-oxidation of other volatile organic compounds (VOCs). The series of aliphatic aldehydes, from $\mathrm{C}_{3}-\mathrm{C}_{10}$, have been measured in ambient Los Angeles air samples at levels ranging from 0.41 to $1.09 \mathrm{ppb}$, with nonanal $\left(\mathrm{C}_{9}\right)$ being the most abundant (Grosjean et al., 1996). Ketones such as acetone and 2butanone were observed at similar levels in the same study. While laboratory studies have provided evidence for possible reaction of these carbonyl compounds with concentrated sulfuric acid at room temperature, there is no data available for ice nucleation when these compounds interact with dilute sulfuric acid aerosols at low temperature.

If the water equilibrium is maintained in sulfuric acid aerosols with significant organic content in the atmosphere, the Koop et al. (2000) water activity model predicts that the ice nucleation temperatures for these complex particles would be unchanged from the aqueous sulfuric acid aerosol case. The Koop et al. (2000) model is also potentially applicable even if aerosols are not in equilibrium with atmospheric water vapor, as long as the aerosol organic content can be determined and related to aerosol water activity. However, field measurements have indicated that mixed organic/sulfate aerosol might be less efficient at ice nucleation (DeMott et al., 2003; Cziczo et al., 2004). One possible explanation for this observation is that the presence of organic compounds modifies the water uptake properties of the aerosol, and serves to sever the equilibrium between aerosol water content and atmospheric water vapor.

Given these possibilities and observations, a series of the straight-chain aliphatic $\mathrm{C}_{3}-\mathrm{C}_{10}$ aldehydes, as well as two 
Table 1. Measured infrared absorption cross-sections for organic compounds used in this study. The frequency of measurement is also provided. Cross sections for 2-nonanone and decanal could not be determined due to vapor pressure limitations. Infrared absorption crosssections calculated from NIST data are also shown where available (Thermodynamics Source Database, 2005).

\begin{tabular}{cccc}
\hline Organic Compound & Frequency used $\left(\mathrm{cm}^{-1}\right)$ & Cross section $\left(\mathrm{cm}^{-1}\right.$ torr $\left.^{-1}\right)$ & NIST Cross section $\left(\mathrm{cm}^{-1}\right.$ torr $\left.^{-1}\right)$ \\
\hline acetone & 2977 & $9.78 \mathrm{E}-04$ & $1.45 \mathrm{E}-3$ \\
propanal & 2720 & $2.13 \mathrm{E}-03$ & $2.00 \mathrm{E}-3$ \\
butanal & 2712 & $2.05 \mathrm{E}-03$ & \\
pentanal & 2712 & $2.49 \mathrm{E}-03$ & \\
hexanal & 2712 & $2.04 \mathrm{E}-03$ & \\
heptanal & 2712 & $8.11 \mathrm{E}-04$ & \\
octanal & 2712 & $1.58 \mathrm{E}-03$ & \\
nonanal & 2712 & $2.04 \mathrm{E}-03$ & \\
\hline
\end{tabular}

ketones, acetone and 2-nonanone, were added to a single composition sulfuric acid aerosol of tropospheric relevance ( $15 \mathrm{wt} \% \mathrm{H}_{2} \mathrm{SO}_{4}$ ) to determine the effects on ice nucleation. The findings of the present work indicate that the physical properties of the organics contained in the aerosol may play a key role in determining atmospheric ice nucleation mechanisms and temperatures.

\section{Experimental}

\subsection{Ice nucleation}

The experimental apparatus used for measuring ice nucleation from mixed carbonyl and sulfuric acid particles is shown in Fig. 1. Submicrometer sulfuric acid aerosols were generated using an atomizer (TSI Model 3076) with a Harvard apparatus syringe pump. A $30 \mathrm{wt} \%$ sulfuric acid solution, prepared with distilled, deionized water, was fed at $0.3 \mathrm{~mL} / \mathrm{min}$ through the atomizer with pre-purified (PP)$\mathrm{N}_{2}$ as the carrier gas. After atomization, the sulfuric acid aerosols were conditioned by passing through a sulfuric acid conditioning bath, which had the effect of adding water to the particles to achieve the desired $15 \mathrm{wt} \%$ composition. A flow of organic vapor was merged with the aerosol flow by passing PP- $\mathrm{N}_{2}$ through a reservoir of organic liquid.

The partial pressure of the organic vapor was controlled by holding the organic reservoir at fixed temperatures ranging from $-78^{\circ} \mathrm{C}$ to $+24 \circ \mathrm{C}$. In order to quantify the amount of organic to which the sulfuric acid aerosols were exposed, the actual partial pressures of organics were measured in the flow tubes using the infrared absorbance of the organic in the absence of aerosols. Based on a calculation involving aerosol concentration, aerosol growth, and partial pressure of organic, the partial pressure in the absence of and in the presence of aerosols was estimated to be the same, and was used as such throughout this study. Although some infrared absorption cross-sections were available in the literature, infrared absorption cross-sections were separately determined for most compounds in the present study and used to calculate partial pressures. An infrared gas cell, with a pathlength of $8.25 \mathrm{~cm}$, was filled with the organic compound of interest to pressures ranging from 0.5 to 10.0 torr, measured with a baratron capacitance manometer. All spectra collected were referenced to the background spectrum of the empty gas cell. The absorbance peak height of the aldehydic carbon-hydrogen stretch around $2712 \mathrm{~cm}^{-1}$ was used to determine the cross-sections for aldehydes while the aliphatic carbon-hydrogen stretch at $2977 \mathrm{~cm}^{-1}$ was used for acetone. Measured infrared absorption cross-sections are listed in Table 1. The NIST database reference spectra were used to calculate cross-sections of $2.00 \times 10^{-3} \mathrm{~cm}^{-1} \mathrm{torr}^{-1}$ and $1.45 \times 10^{-3} \mathrm{~cm}^{-1}$ torr $^{-1}$ for propanal and acetone, respectively (Thermodynamics Source Database, 2005). Our measured values of $2.13 \times 10^{-3} \mathrm{~cm}^{-1}$ torr $^{-1}$ and $9.78 \times 10^{-4} \mathrm{~cm}^{-1}$ torr $^{-1}$ for propanal and acetone, respectively, agree reasonably well with the NIST database. Crosssections could not be determined experimentally for 2nonanone or decanal due to vapor pressure limitations.

The particles and organic vapor were allowed to mix for approximately one minute before entering the aerosol flow tubes. After the mixing period, the organic/sulfuric acid particles entered the temperature-controlled flow tube apparatus similar to that used by Prenni et al. (2001b) and Wise et al. (2004). The aerosol passes through three tubes, with inner diameters of $4 \mathrm{~cm}$ that are cooled with recirculated methanol from Neslab refrigerators. The first in the series of flow tubes $(90 \mathrm{~cm})$ was held at a constant temperature of $-19.0^{\circ} \mathrm{C}\left( \pm 1.5^{\circ} \mathrm{C}\right)$ for all experiments. This conditioning tube served to set and maintain the sulfate to water ratio of the aerosols and to precool the aerosols. Fourier transform infrared (FTIR) spectroscopy was used to observe the aerosols in the third tube $(80 \mathrm{~cm})$. The temperature in this observation region was varied over the range necessary to observe ice nucleation, from $-30^{\circ} \mathrm{C}$ to $-75^{\circ} \mathrm{C}$. A transition tube $(\sim 75 \mathrm{~cm})$ was used between the first and third regions, each end cooled to the temperature of the closest tube, in 
order to ensure time for the aerosol to reach the observation tube temperature before detection with FTIR spectroscopy. Flow tube temperatures were measured with thermocouples placed in the aerosol flow. The thermocouples were periodically calibrated against a reference temperature to ensure accurate temperature measurements. Although standard error for thermocouples is $\pm 1.0^{\circ} \mathrm{C}$, we never observed deviation greater than $\pm 0.6^{\circ} \mathrm{C}$ from a reference temperature measurement, even at the coldest temperatures used.

The aerosol composition in the observation region was determined using FTIR spectroscopy. The water to sulfate ratio was determined using FTIR spectral calibrations of the ratio of the OH peak $\left(3650-2409 \mathrm{~cm}^{-1}\right)$ to the sulfate peak (1470$820 \mathrm{~cm}^{-1}$ ) (Anthony et al., 1995; Bertram et al., 1996). The FTIR spectral calibrations were used to verify the water to sulfate ratio remained constant after the addition of the organic compounds. The organic content of sulfuric acid aerosols was determined using a Mie scattering analysis, as contributions from gas phase organics contribute to the organic absorbance bands. This process will be described in detail in the next experimental section.

In a typical ice nucleation experiment, the initial observation tube temperature is set well above the temperature at which the aerosol should nucleate ice. At this temperature, the aerosol composition is verified as described above. Near the freezing point, the temperature of the observation region is decreased in $\sim 1.5^{\circ} \mathrm{C}$ increments. The phase of the aerosol is monitored at each temperature using FTIR spectroscopy. Several distinct spectral changes occur near the freezing point including shifts of the -OH stretch, centered at $\sim 3300 \mathrm{~cm}^{-1}$, to lower frequencies and the $\mathrm{H}_{2} \mathrm{O}$ librational band at $\sim 800 \mathrm{~cm}^{-1}$ to higher frequencies. Each collected spectrum is subtracted from the previous, warmer spectrum. A modified version of the Hung et al. (2002) formalism is used to quantify ice nucleation temperatures. Instead of the $690-880 \mathrm{~cm}^{-1}$ region used by both Wise et al. (2004) and Hung et al. (2002) for ammonium sulfate, a combination of the variance of both the $\mathrm{OH}$ stretch and $\mathrm{H}_{2} \mathrm{O}$ libration regions from $\left(3700-3200 \mathrm{~cm}^{-1}\right.$ and $\left.940-660 \mathrm{~cm}^{-1}\right)$ was used to determine ice nucleation temperatures. The product of the variance of the two spectra in these spectral regions was used in order to give them equal weighting. This product was normalized by the change in temperature and then plotted as a function of the temperature of the observation region. The onset freezing temperature was defined when qualitative changes, due to ice nucleation, were observed in both spectral regions. The peaks of these variances are defined as the ice nucleation temperatures in this study. Therefore, onset nucleation temperatures were on average, $1.5-3.0^{\circ} \mathrm{C}$ warmer than those reported throughout. Although the organics used in this study do contain some absorption features in these spectral areas, no interference with the variance analysis was observed. Steps of $1.5^{\circ} \mathrm{C}$ were taken to construct the variance plots because $1.5^{\circ} \mathrm{C}$ was empirically observed to be the approximate uncertainty in the determination of the freezing temperature, which may be caused by slightly varying aerosol composition. Sulfuric acid aerosol composition was checked, using the infrared calibrations, at the end of most experiments to ensure that a relatively constant base aerosol composition was present throughout the ice nucleation experiment. Organic compounds used in this study were acetone, propanal, butanal, pentanal, hexanal, heptanal, octanal, nonanal, 2-nonanone, and decanal. All chemicals were purchased from Sigma-Aldrich and were of greater than $95 \%$ purity. All experiments were conducted using $15 \mathrm{wt} \%$ $( \pm 2 \mathrm{wt} \%)$ sulfuric acid composition as the precursor aqueous sulfuric acid aerosol.

\subsection{Organic content from Mie scattering analysis}

In order to quantify the amount of organic incorporated into the sulfuric acid particles, a Mie scattering analysis was performed to determine aerosol diameter before and after organic addition. A Fortran program adapted from Bohren and Huffman (1983) was used to calculate extinction spectra to fit experimental spectra collected at $T_{\mathrm{obs}} \sim-49^{\circ} \mathrm{C}$. This temperature limit was imposed by the ice nucleation temperature for sulfuric acid at this composition, as the scattering analysis is valid for unfrozen aerosol only. All calculations were performed assuming spherical particles with a log-normal size distribution and a geometric standard deviation (GSD) of 2.0. The optical constants for sulfuric acid were taken from the work of Myhre et al. (2003) who parameterized them over the concentration range from $12-81 \mathrm{wt} \% \mathrm{H}_{2} \mathrm{SO}_{4}$ and temperature range from $300-220 \mathrm{~K}$. Due to the absence of optical constants data for the organic compounds at the temperatures used in this study, optical properties of sulfuric acid were assumed in this analysis. To most accurately fit the measured spectra, only the region where scattering features dominate the extinction was used, therefore values at wavenumbers below $2000 \mathrm{~cm}^{-1}$ were excluded. Extinction values in the region from 3000 to $2700 \mathrm{~cm}^{-1}$ were also eliminated due to interferences from organic $\mathrm{CH}$ stretches, when present. The region above $3500 \mathrm{~cm}^{-1}$ was weighted more heavily than the remaining portions of the spectrum because the extinction is totally due to scattering in this region. To determine if a distribution of pure organic particles was present in these experiments, investigative experiments were performed where the organic compounds were flowed through the low temperature flow tubes in the absence of sulfuric acid aerosols, and FTIR spectra were collected. Under these conditions, the IR spectra indicated no nucleation of organic particles, i.e. no Mie scattering was observed in the 5000 to $3500 \mathrm{~cm}^{-1}$ region. These spectra were also identical to reference gas phase spectra.

The results from this scattering analysis were used to determine aerosol organic molality $(\mathrm{m}=$ moles solute $/ \mathrm{kg}$ of solution). The difference in aqueous sulfuric acid aerosol mean diameters, before and after organic addition, was converted to an aerosol volume change. The increase in aerosol 
diameter was assumed to be due only to the incorporation of organic into the aerosol. This volume increase, along with the molecular weight of the organic compound, was used to calculate moles of organic, in order to calculate organic aerosol molaltiy. Then, the total aerosol volume with an estimate of aerosol density based on sulfuric acid, water, and the organic compound densities, were combined with moles of organic to calculate the aerosol organic molarity $(\mathrm{M}=$ moles solute/L of solution).

\section{Results and discussion}

\subsection{Scattering results}

In evaluation of the Mie scattering analysis, the choice of the geometric standard deviation (GSD) has a strong effect on the calculated aerosol diameter, the value of the GSD has no effect on the calculated relative aerosol diameters for two different aerosol distributions. An investigation of the effects of GSD on percent organic is summarized in Table 2. The GSD input to the Mie scattering analysis was varied over the range of 1.4 to 2.6. Fits to spectra of sulfuric acid aerosol both before and after the exposure to 0.13 torr acetone were obtained with the Mie scattering analysis. It can be seen that while the absolute diameters varied widely over the range of GSD, the percent organic remained essentially unchanged. Therefore, since our analysis depends only on changes in aerosol diameter, the choice of GSD has no effect on the calculated results.

The Mie scattering analysis used above assumes a lognormal distribution. However, if the distributions are not lognormal, the calculated relative aerosol diameters might be in error. An alternative Mie scattering analysis (Zasetsky et al., 2004), one not assuming a log-normal aerosol size distribution, was also used to analyze a portion of the data. From the tests with this method, it was found that the aerosol distributions were indeed log-normal. Therefore, the log-normal distribution is a reasonable assumption in this case, and the simpler scattering analysis model of Bohren and Huffman (1983) was used. Overall, in the spectral regions (i.e. the scattering region) used to determine mean aerosol diameter, there is good agreement between the observed and calculated spectra, and the differences in the two spectra are due to the absorption component of the optical constants. This agreement is retained even upon addition of the organic to sulfuric acid aerosols. The variation in diameter of the sulfuric acid aerosol among experiments, before the addition of organic, determined by examining the Mie scattering fits, is $5.0 \%$. In order to determine the uncertainty in the diameters calculated by the Mie scattering analysis, the RMS errors from calculated spectra over a range of diameters close to the bestfit diameter were compared. Then, a RMS error difference of $50 \%$ was chosen as an unacceptable fit. This difference translated into an approximate $5.0 \mathrm{~nm}$ uncertainty in diameter. This uncertainty was propagated through the percent

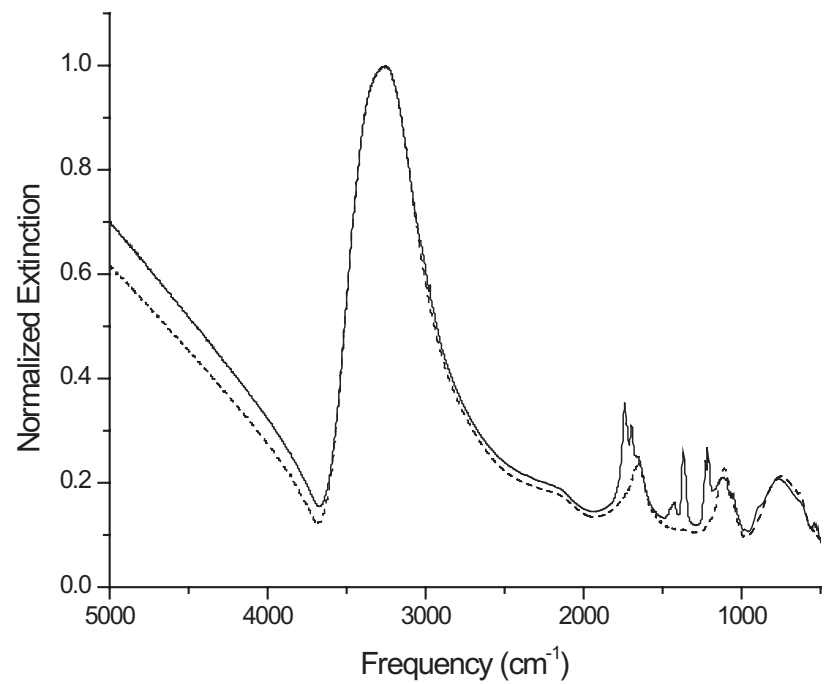

Fig. 2. Infrared extinction spectra for increasing partial pressure exposure to acetone. $15 \mathrm{wt} \% \mathrm{H}_{2} \mathrm{SO}_{4}$ aerosol exposed to 0 Torr (dashed) and 0.435 Torr (solid). The spectra are normalized to maximum extinction. The region above $3500 \mathrm{~cm}^{-1}$ increases in slope with increasing exposure to acetone.

organic and organic molality calculations. However, the accuracy of this method is limited by the assumption that the addition of organic compounds does not significantly modify the optical constants of the aerosol.

Figure 2 shows the increase in the slope of the normalized extinction spectra above $3500 \mathrm{~cm}^{-1}$ upon exposure of sulfuric acid aerosols to increasing partial pressures of acetone. Also, absorption features due to acetone are observed to grow in between 1000 and $2000 \mathrm{~cm}^{-1}$. The increase in slope corresponds to an aerosol size increase caused by increasing the partial pressure exposure of organic vapor. For example, using the procedure discussed above to obtain the organic molality from the diameter difference determined from the scattering observed in the dashed spectrum (no acetone) when compared to the scattering observed in the solid spectrum ( 0.435 torr acetone) leads to the result that the acetoneexposed aerosol is $5.1 \mathrm{~m}$ in acetone, which corresponds to approximately a $30 \mathrm{~nm}$ increase in diameter. To determine if the organic uptake was due to acid-catalyzed chemistry, control experiments were performed with aqueous ammonium sulfate $(\sim 30 \mathrm{wt} \%)$ as the base aerosol. A qualitatively similar diameter increase was observed, leading to the conclusion that the uptake of the organic is due purely to physical processes (the solubilities of organics in the dilute sulfuric acid and ammonium sulfate aerosols are probably near their pure water values). This result is at odds with the possibility that acid-catalyzed reactions on the time-scale (one minute) and at the temperature conditions (room temperature mixing) of these experiments are responsible for the organic uptake. Also, spectral changes that would be indicative 
Table 2. Investigation of the effect of geometric standard deviation (GSD) on calculated diameters (D) and \% organic calculated using Mie scattering calculations. Fits to spectra of sulfuric acid aerosol both before and after exposure to 0.13 torr acetone were obtained with the Mie scattering analysis. RMS errors are the difference between the experimental spectrum and the calculated fit.

\begin{tabular}{lcccccc}
\hline $\mathrm{GSD}$ & 2.6 & 2.2 & 2.0 & 1.8 & 1.6 & 1.4 \\
\hline $\mathrm{D}\left(\mathrm{H}_{2} \mathrm{SO}_{4}, \mathrm{~nm}\right)$ & 120.8 & 210.2 & 278.2 & 401.8 & 569.0 & 794.9 \\
$\mathrm{RMS} \mathrm{error}($ final $)$ & 0.0192 & 0.0192 & 0.0192 & 0.0192 & 0.0192 & 0.0193 \\
$\mathrm{D}\left(\mathrm{H}_{2} \mathrm{SO}_{4}\right.$ with acetone, $\left.\mathrm{nm}\right)$ & 129.0 & 224.5 & 297.5 & 429.3 & 607.8 & 848.1 \\
$\mathrm{RMS}$ error (final) & 0.0151 & 0.0151 & 0.0151 & 0.0151 & 0.0150 & 0.0151 \\
\% organic & 17.9 & 18.0 & 18.2 & 18.0 & 18.0 & 17.7 \\
\hline
\end{tabular}

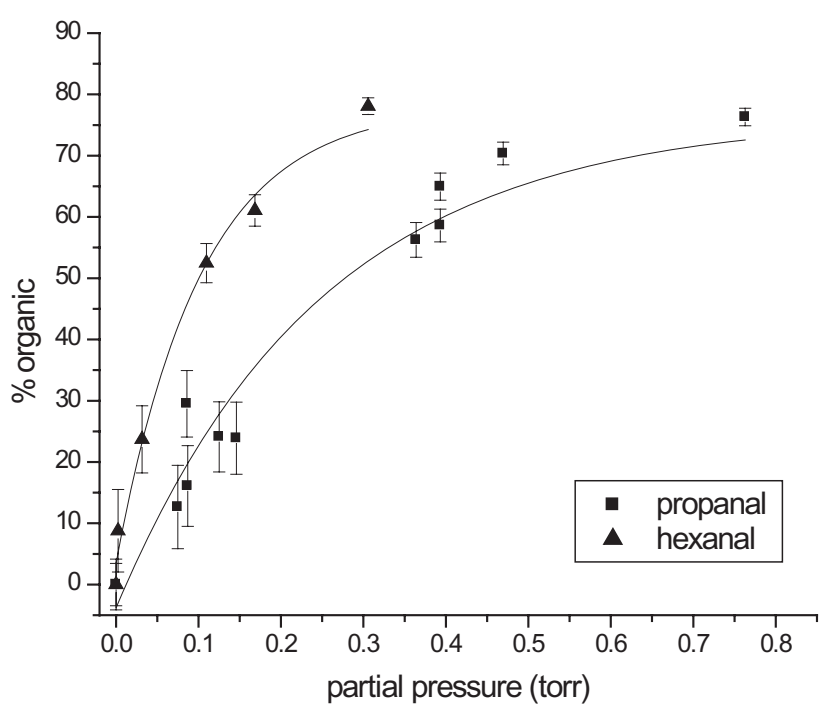

Fig. 3. Dependence of organic uptake (organic content) on organic and partial pressure exposure. Percentage organic determined from Mie scattering analysis, and error bars reflect the uncertainty in this calculation. The curves shown are non-linear fits to the data.

of these acid-catalyzed reactions (i.e. carbonyl stretch shift) were absent. In addition, ongoing bulk kinetics experiments in our laboratory indicate that the one-minute timescale in the present experiments is much too short for acid-catalyzed reactions to occur on $15 \mathrm{wt} \%$ sulfuric acid aerosols at room temperature.

The dependence of organic uptake on the identity of the organic compound and partial pressure exposure can be seen in Fig. 3. The lower vapor pressure organic, hexanal, achieves higher uptake at lower partial pressure exposures when compared to an organic of higher vapor pressure, propanal. Percentage organic was determined from Mie scattering analysis, and error bars reflect the uncertainty in this calculation. The curves shown are non-linear fits to the data. It has been assumed that the addition of organic compounds does not significantly modify the optical constants of the aerosol. The error generated by this assumption is not included in the error bars. It can also be seen that the aerosols approach $100 \%$ organic composition at increased organic exposures. Experiments were also performed to observe the organic uptake dependence on observation tube temperature. A consistent size increase was observed to occur with decreasing tube temperature. Therefore, water activity was not fixed in the experiments described in this paper, as it changed with observation temperature, unlike the experiments by Wise et al. (2004) on non-volatile dicarboxylic acids. Also as a result, organic content determinations reported herein must be considered as lower limits as all measurements were made at temperatures above the freezing point of the particles.

\subsection{Ice nucleation}

The ice nucleation temperature for pure $15 \mathrm{wt} \% \mathrm{H}_{2} \mathrm{SO}_{4}$ aerosol was first measured and compared with previous results. Previous studies have investigated the homogeneous nucleation of $15 \mathrm{wt} \%$ sulfuric acid using a variety of techniques including low temperature flow tubes with FTIR spectroscopy (Bertram et al., 1996; Cziczo and Abbatt, 2001; Prenni et al., 2001b), optical microscopy (Koop et al., 1998), and a continuous flow diffusion chamber (Chen et al., 2000). There remains some spread across the ice nucleation results for this composition using these various techniques. The freezing variance plot we obtain for $15 \mathrm{wt} \% \mathrm{H}_{2} \mathrm{SO}_{4}$ is shown in Fig. 4 with a freezing temperature of $-54.0^{\circ} \mathrm{C}$. Of the previous studies that observed sulfuric acid aerosol ice nucleation temperatures, the result from this set of experiments agrees within error with results from a flow tube study (Prenni et al., 2001b), an optical method (Koop et al., 1998), and a study using the continuous flow diffusion chamber (Chen et al., 2000). These studies report freezing temperatures of $-53.0^{\circ} \mathrm{C}$ for $15 \mathrm{wt} \% \mathrm{H}_{2} \mathrm{SO}_{4}$ aerosol. The Koop et al. (2000) water activity model predicts a freezing temperature of $-52.0^{\circ} \mathrm{C}$. Therefore, our results, within error $\left( \pm 1.5^{\circ} \mathrm{C}\right)$, are in agreement with current literature values for sulfuric acid aerosol, as well as the Koop et al. (2000) model. All subsequent ice nucleation results should be viewed as a change from the $15 \mathrm{wt} \%$ sulfuric acid aerosol ice nucleation result of $-54.0^{\circ} \mathrm{C}$. 


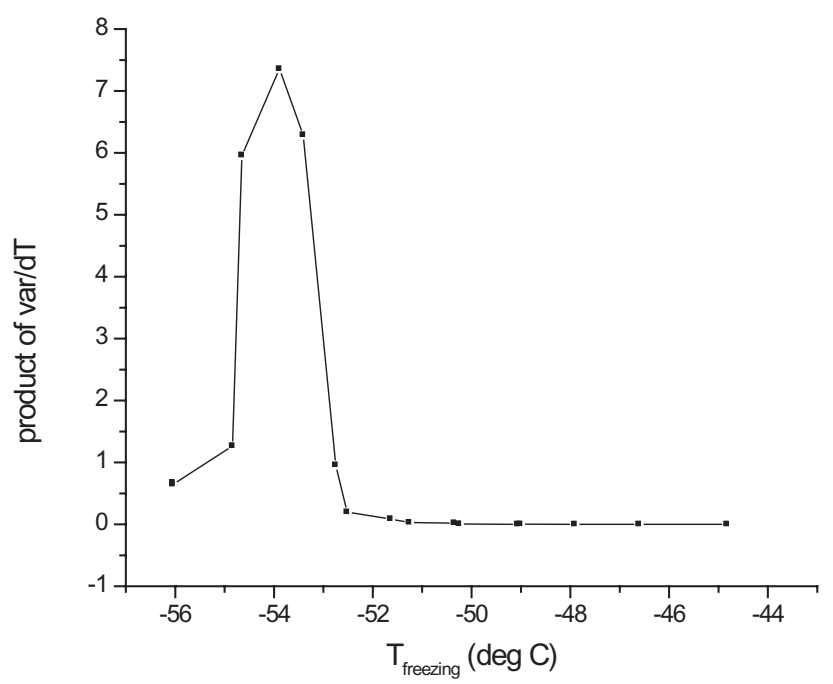

Fig. 4. A variance plot for $15 \mathrm{wt} \% \quad \mathrm{H}_{2} \mathrm{SO}_{4}$ aerosol. $T_{\text {freezing }}=-54.0^{\circ} \mathrm{C}$. Error in $T_{\text {freezing }}$ was found to be $\pm 1.5^{\circ} \mathrm{C}$ due to slight variations in aerosol concentration.

An extensive ice nucleation study of sulfuric acid aerosols as a function of partial pressure exposure of propanal was conducted, and the results are shown in Fig. 5. In general, there are two regimes into which these results can be divided. At propanal partial pressures less than 0.15 torr, the freezing temperature linearly decreased with increasing propanal pressure, while above 0.15 torr, the freezing temperature remained constant. A linear fit is shown for the data below 0.15 torr. These results can be explained by the existence of a single-phase aerosol at partial pressures below 0.15 torr, where propanal is soluble in the aqueous sulfuric acid aerosol. Therefore, as the partial pressure increases, the molality increases, while the water activity decreases, qualitatively adhering to the Koop et al. (2000) water activity model for homogeneous ice nucleation. The interpretation of the plateauing of the ice nucleation temperatures at about 0.15 torr is that the aerosol apparently reaches the propanal solubility limit. Therefore, any additional propanal added is not soluble and forms an organic phase on the mixed sulfuric acid/propanal aerosol core, and the propanal molality and water activity of the inner aqueous aerosol remains constant. This was tested to partial pressure exposures as high as 1.0 torr. Beyond these exposure levels, quantitative ice nucleation determination became increasingly difficult due to the strong propanal absorption features in the infrared extinction spectra.

From these results, if the 0.15 torr propanal-exposed aerosols are taken as the case where the propanal is dissolved up to its solubility limit, then the results from the Mie scattering analysis indicate that the propanal content of the aerosols, at $-49^{\circ} \mathrm{C}$ is $25 \%$, by volume ( $4.0 \mathrm{M}$ and $230 \mathrm{~g} / \mathrm{L}$ ). The bulk, room temperature, solubility of propanal in water, as shown

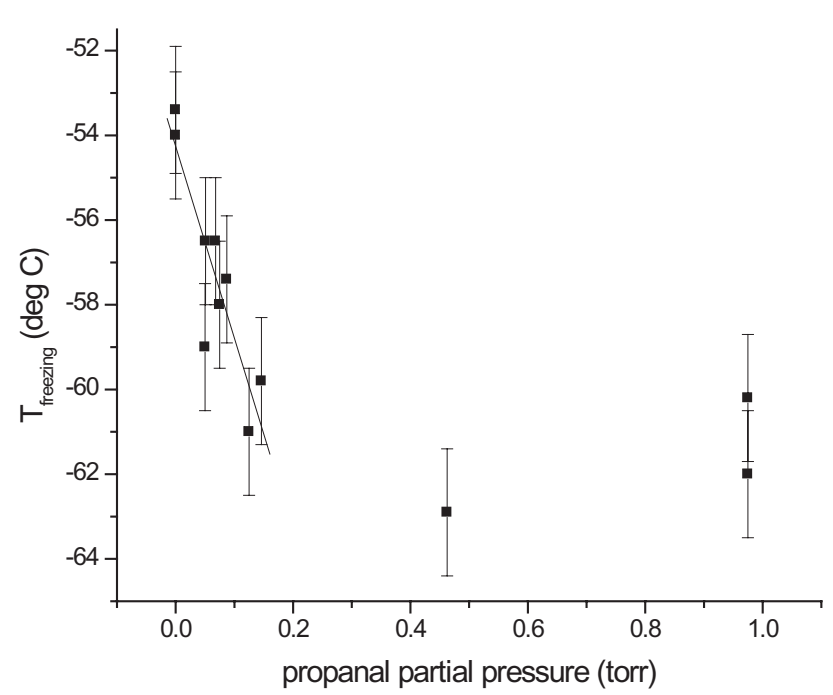

Fig. 5. Freezing temperatures $\left({ }^{\circ} \mathrm{C}\right)$ as a function of propanal partial pressure (Torr). A single-phase aerosol is proposed for exposures $<0.15$ Torr, a linear fit to this portion of data is shown. At partial pressures above this value, a two-phase aerosol is thought to exist, saturated in propanal.

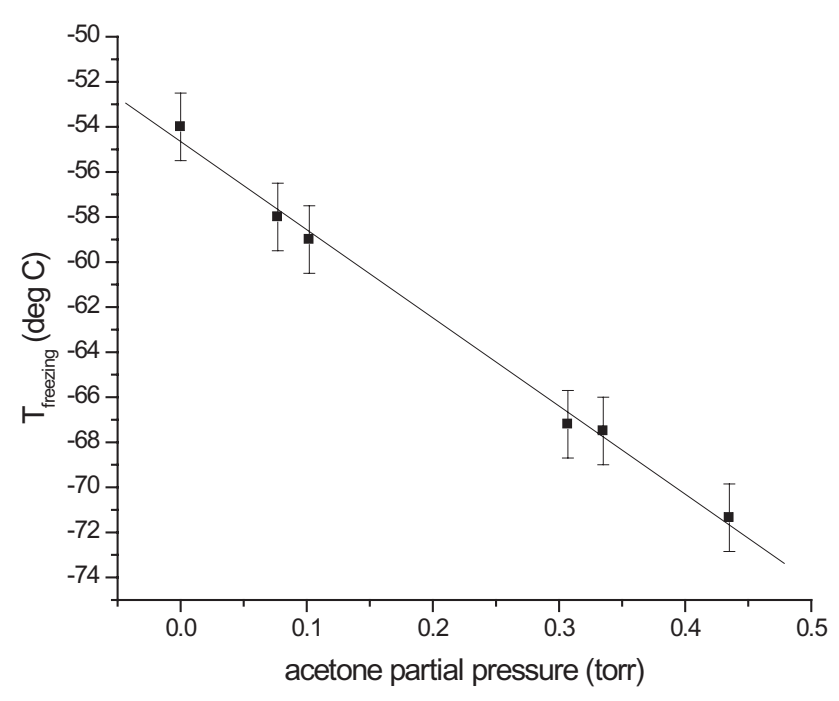

Fig. 6. Freezing temperatures $\left({ }^{\circ} \mathrm{C}\right)$ as a function of acetone partial pressure (torr). A single-phase aqueous aerosol exists at all partial pressures exposure for which ice nucleation temperature could be determined. A linear fit to the data is shown. Error bars are $\pm 1.5^{\circ} \mathrm{C}$.

in Table 3 is $306 \mathrm{~g} / \mathrm{L}$, which corresponds to $38 \%$ by volume $(5.3 \mathrm{M})$. Despite the differences in temperature, this comparison is useful to relate the solubility limit determined by the Mie scattering analysis to that known from bulk measurements.

A similar study of the effect of partial pressure exposure on ice nucleation was also conducted for sulfuric acid aerosols exposed to acetone. Figure 6 shows a plot for acetone similar to that shown in Fig. 5 for propanal, though 
Table 3. Physical properties of organic compounds used in this study. Data compiled from Hazardous Substances Data Bank (2005) and Thermodynamics Source Database (2005).

\begin{tabular}{lcc}
\hline Organic Compound & Melting Temperature $\left({ }^{\circ} \mathrm{C}\right)$ & Water Solubility $\left(\mathrm{mg} / \mathrm{L} \mathrm{H}_{2} \mathrm{O}\right) @ 25^{\circ} \mathrm{C}$ \\
\hline acetone & -95 & miscible \\
propanal & -80 & 306000 \\
butanal & -97 & 71000 \\
pentanal & -91 & 11700 \\
hexanal & -56 & 6000 \\
heptanal & -43 & 1550 \\
octanal & -27 & 560 \\
nonanal & -18 & 96 \\
2-nonanone & -8 & 1.4 \\
decanal & -6 & 20 \\
\hline
\end{tabular}

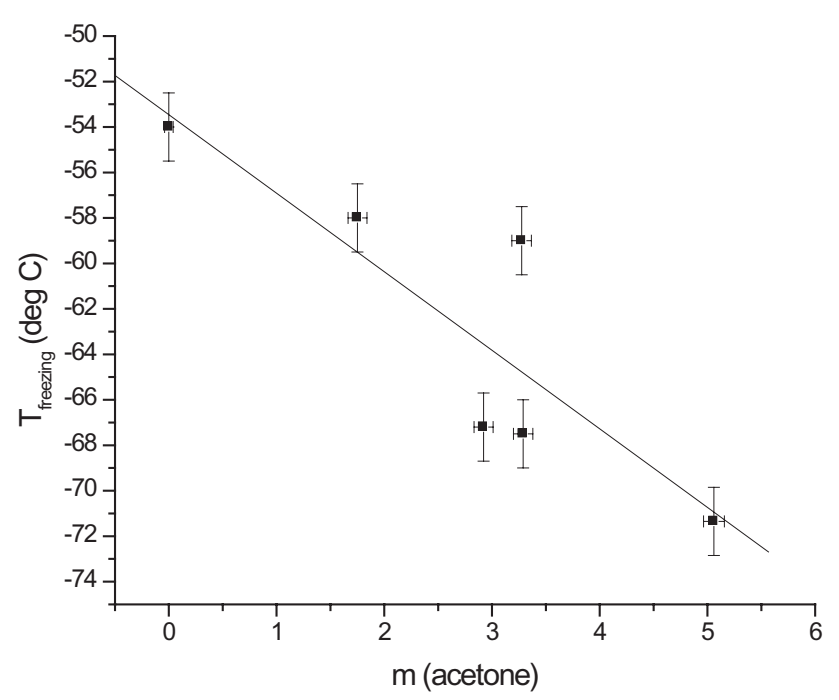

Fig. 7. Freezing temperatures $\left({ }^{\circ} \mathrm{C}\right)$ as a function of acetone molality. Molality is determined from aerosol size increase as determined by a Mie scattering analysis of infrared extinction spectra. A linear fit to the data is shown. Temperature error bars are $\pm 1.5^{\circ} \mathrm{C}$, and molality error bars reflect the uncertainty in the Mie scattering calculation of aerosol diameter.

over a smaller range of partial pressures. In contrast to the propanal case, it can be seen that increasing amounts of acetone cause a decrease in freezing temperatures over the entire range studied. The increased solubility of acetone (as compared to propanal) in sulfuric acid aerosol is the likely cause of the difference. As a result, ice nucleation temperatures could not be measured at any partial pressure exposures higher than 0.45 torr $\left(-71.5^{\circ} \mathrm{C}\right)$ due to flow tube cooling system limitations. As more acetone is taken up by the particles, the molality increases while the water activity decreases, again qualitatively adhering to the Koop et al. (2000) water activity theory for homogeneous ice nucleation. In addition, because acetone is more soluble in $15 \mathrm{wt} \%$ sulfuric acid than is propanal, the ice nucleation depression is more pronounced.

Figure 7 shows the same aerosol ice nucleation temperature data as in Fig. 6, but is plotted against aerosol acetone molality. Aerosol acetone molality was determined from the aerosol size increase determined from a Mie scattering analysis of aerosol infrared extinction spectra. In order to quantify the decrease in temperature with aerosol acetone molality, an analysis involving the empirical parameter, $\lambda$, was used (Rasmussen and MacKenzie, 1972; Prenni et al., 2001b; DeMott, 2002). The parameter $\lambda$ is the ratio of the depression of the ice nucleation temperatures of solute-containing droplets to bulk solute-containing solutions each relative to pure water (i.e., $\lambda$ would be equal to unity in the absence of increased supercooling effects over those of water). According to Eq. (1), the product of lambda, $\lambda$, and the melting temperature depression, $\Delta T_{m}$, equals the freezing temperature depression, $\Delta T_{f}$ (Rasmussen and MacKenzie, 1972; Prenni et al., 2001b; DeMott, 2002). Then, Eq. (2) is the empirical equation for bulk melting point depression due to solute addition (Atkins, 1997).

$$
\begin{aligned}
& \Delta T_{f}=\lambda \cdot \Delta T_{m} \\
& \Delta T_{m}=K_{f} \cdot m
\end{aligned}
$$

This equation relates the bulk melting temperature depression, $\Delta T_{m}$, to the product of $K_{f}$, the solvent freezing point depression constant, and $m$, molality. In this analysis method, the observed freezing (nucleation) point depression can be related to solute molality, $m$, according to Eqs. (1) and (2) where $K_{f}$ is the freezing point depression constant for, in this case, $15 \mathrm{wt} \% \mathrm{H}_{2} \mathrm{SO}_{4}$ and $\Delta T_{f}$ and $\Delta T_{m}$ are the freezing and melting temperature depressions, respectively.

The literature values reported for $\lambda$ range from 1.4 to 2.2 for various salt solutions, with a typical value of 1.7 (DeMott, 2002). Using 1.7 for $\lambda$ and $K_{f}$ for water, $1.86^{\circ} \mathrm{C} / \mathrm{m}$, the slope

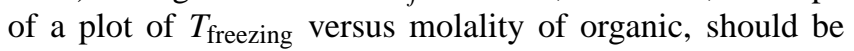




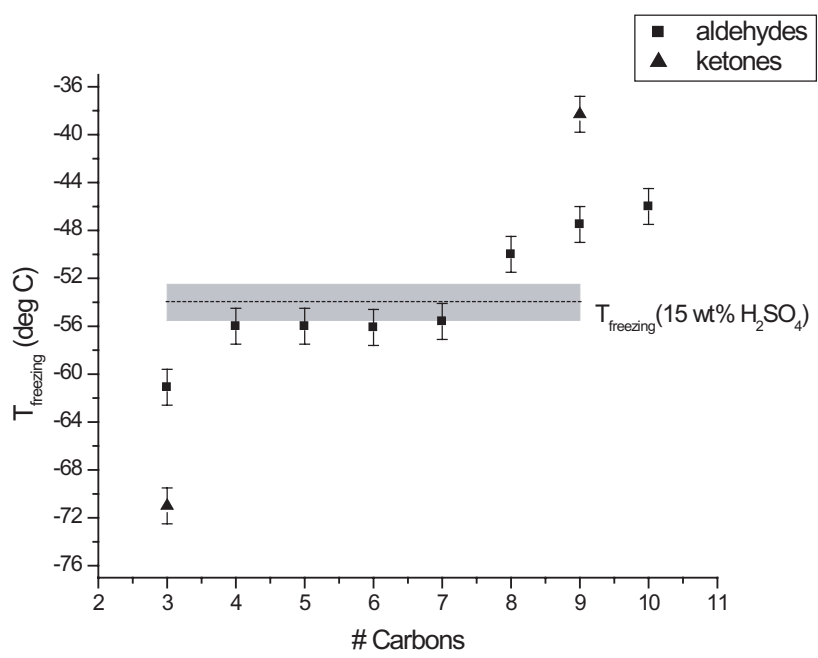

Fig. 8. Freezing temperatures $\left({ }^{\circ} \mathrm{C}\right)$ as a function of organic carbon chain length. Results, except for acetone, are shown for aqueous aerosols saturated with organic. The arrow indicates the possible further decrease in ice nucleation temperature for the saturated acetone/aqueous sulfuric acid aerosol. The water activity of particles with $\mathrm{C}_{4}$ and longer compounds are likely of constant water activity, though a direct measure of the water activity of the particles was not possible. Error bars on individual data points and the $15 \mathrm{wt} \%$ $\mathrm{H}_{2} \mathrm{SO}_{4}$ freezing result (shaded box) are $\pm 1.5^{\circ} \mathrm{C}$.

around $-3.2^{\circ} \mathrm{C} / \mathrm{m}$. The fit to the data from these experiments gives a line with a slope of $-3.5^{\circ} \mathrm{C} / \mathrm{m}$. Alternatively, using the experimental slope and $K_{f}$ for water, a value of 1.9 is determined for $\lambda$, which is well within the typical range. Unfortunately, melting point as a function of solution molality data is not available for these solutions, which is necessary to calculate water activity values. Therefore, a direct comparison to Koop et al. (2000) model predictions is not possible in this case. Despite this, using the empirical relationships described above, the experimental results can be fit.

Because the partial pressure of the organics is measured and the aerosol molarity is determined using the Mie scattering analysis, it is possible to carry out a Henry's law analysis to determine the solubilities of these gases in $15 \mathrm{wt} \% \mathrm{H}_{2} \mathrm{SO}_{4}$. Henry's law is used, in the dilute solution limit, to define the solubility or concentration at equilibrium, of a gas, $\mathrm{A}$, in aqueous solutions, $[\mathrm{A}]_{(\mathrm{aq})}$, as related to the partial pressure of the gas above the solution, $p_{\mathrm{A}}$, according to Eq. (3).

$[\mathrm{A}]_{(\mathrm{aq})}=H_{\mathrm{A}} p_{\mathrm{A}}$

Henry's law solubilities, $H$, of $22000 \mathrm{M} / \mathrm{atm}$ and $6600 \mathrm{M} / \mathrm{atm}$ were determined for propanal and acetone, respectively, at $-50.0^{\circ} \mathrm{C}$ in $15 \mathrm{wt} \%$ sulfuric acid aerosols. No literature Henry's law values exist for propanal in sulfuric acid, while effective Henry's law solubilites for acetone exist in the literature for $40 \mathrm{wt} \%<\mathrm{H}_{2} \mathrm{SO}_{4} \mathrm{wt} \%$ $<50 \mathrm{wt} \%$ solutions at around $-50^{\circ} \mathrm{C}$ (Kane et al., 1999; Klassen et al., 1999; Imamura and Akiyoshi, 2000). These
Table 4. Ice nucleation results versus organic compound added to $15 \mathrm{wt} \%$ sulfuric acid aerosols. Ice nucleation was observed for $15 \mathrm{wt} \%$ sulfuric acid aerosol at $-54.0^{\circ} \mathrm{C}$. Partial pressures of organic compounds used were determined using the measured absorption cross-sections. Partial pressure data are not available for 2-nonanone and decanal due to the low vapor pressures of these compounds.

\begin{tabular}{lcc}
\hline Organic added & Partial Pressure Exposure (torr) & $T_{f}\left({ }^{\circ} \mathrm{C}\right)$ \\
\hline acetone & 0.35 & -71.0 \\
propanal & 0.98 & -61.1 \\
butanal & 0.28 & -56.0 \\
pentanal & 0.25 & -56.0 \\
hexanal & 0.34 & -56.1 \\
heptanal & 0.39 & -55.6 \\
octanal & 0.15 & -50.0 \\
nonanal & 0.02 & -47.5 \\
2-nonanone & $*$ & -38.3 \\
decanal & $*$ & -46.0 \\
\hline
\end{tabular}

values range from $13800 \mathrm{M} / \mathrm{atm}$ to $21000 \mathrm{M} / \mathrm{atm}$ with errors ranging from $33 \%$ to $50 \%$. Also, no reaction is observed in this acetone/dilute sulfuric acid aerosol system, which may also reconcile the lower Henry's law constant for acetone observed here when compared with the Henry's law constant derived from a system in which acetone is reactive (40-50 wt\% sulfuric acid) (Kane et al., 1999; Klassen et al., 1999; Imamura and Akiyoshi, 2000). These Henry's law results apply in the dilute solution regime, and cannot, necessarily, be compared with bulk solubility data.

Results from the three carbon organics, propanal and acetone, demonstrate the depression of ice nucleation temperatures due to solubility effects. To further investigate the effects of organics with different physical properties, the effect of increasing carbon chain length was also explored. Results from these experiments are summarized in Fig. 8 and Table 4. All ice nucleation results, with the exception of acetone for which only an upper limit was established, are shown for aqueous sulfuric acid aerosols saturated with the organic (i.e. in the plateau region of Fig. 3). For the organics from butanal $\left(\mathrm{C}_{4}\right)$ to heptanal $\left(\mathrm{C}_{7}\right)$, ice nucleation temperatures are, within error, essentially the same as for $15 \mathrm{wt} \%$ $\mathrm{H}_{2} \mathrm{SO}_{4}$ aerosols. In contrast, the compounds from octanal $\left(\mathrm{C}_{8}\right)$ to decanal $\left(\mathrm{C}_{10}\right)$ exhibited freezing temperatures higher than that observed for $15 \mathrm{wt} \% \mathrm{H}_{2} \mathrm{SO}_{4}$ aerosols. The water activity of particles with $\mathrm{C}_{4}$ and longer compounds are likely equal to the value for pure sulfuric acid particles, though a direct measure of the water activity of the particles was not possible.

The physical properties of the organic compounds used in these studies are shown in Fig. 9 and Table 3 and are useful to consider when interpreting these results (Hazardous Substances Data Bank, 2005; Thermodynamics Source 


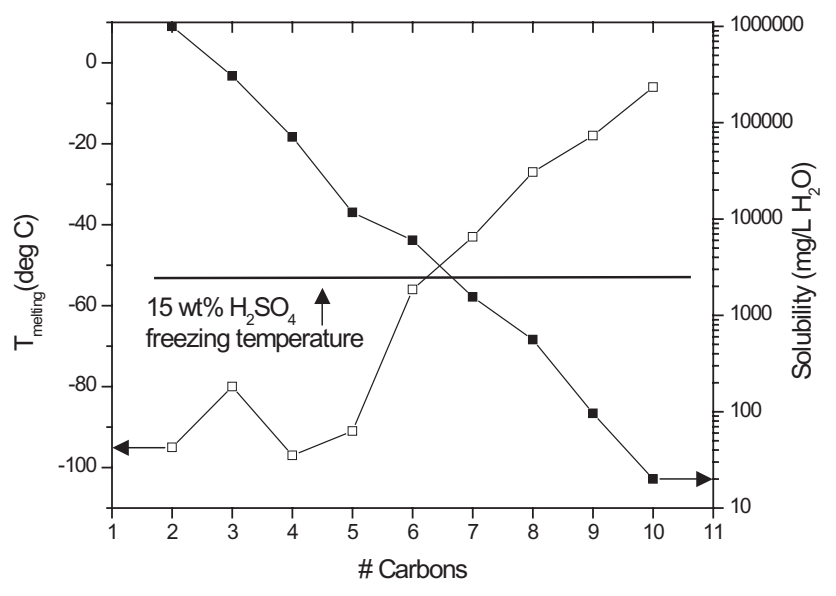

Fig. 9. Melting points (open squares) and solubilities (filled squares) of aldehyde compounds used in this study. Data compiled from Hazardous Substances Data Bank (2005) and Thermodynamics Source Database (2005).

Database, 2005). The difference in the ice nucleation results for acetone and propanal were discussed in the previous section as resulting from the difference in the solubility of the two compounds. In both cases, the high solubility of acetone and propanal likely results in a decrease in water activity. On the other hand, the ice nucleation results for the $\mathrm{C}_{8}$ to $\mathrm{C}_{10}$ compounds can be explained by both differences in the solubilities and melting points of these organic compounds. As can be seen in Fig. 9, these compounds have drastically lower water solubilities and higher melting points than the organic compounds discussed earlier. It is a combination of these physical properties that we believe explain the apparent increase in ice nucleation temperatures over the sulfuric acid base case. Since these longer chain compounds are not very soluble, virtually no decrease in water activity should occur and the aerosol might be expected to nucleate ice at the same temperature as $15 \mathrm{wt} \%$ sulfuric acid. However, a coating of these low solubility organic compounds likely forms on the aqueous sulfuric acid aerosols. Unlike the shorter chain compounds, octanal, nonanal, 2-nonanone, and decanal have melting points all above $-25^{\circ} \mathrm{C}$. As a result, the coating formed on the aerosols freezes at temperatures warmer than the inner aqueous sulfuric acid core (as is dictated by the water activity). Therefore, we believe that ice is heterogeneously nucleated by the frozen organic phase in these cases. The ice nucleation temperatures we find are not the same as the bulk organic melting temperatures, which is likely due to supercooling of the organic phase. Unfortunately, supercooling effects are not well known for these organic compounds, and it is not possible to compare the observed supercooling in our mixed aerosols to supercooling in the pure organic compounds.

The addition of the $\mathrm{C}_{4}$ to $\mathrm{C}_{7}$ compounds to aqueous sulfuric acid aerosols causes no change in ice nucleation temper- ature, relative to the sulfuric acid aerosol base case. Based on solubility properties, these compounds are much less soluble than the $\mathrm{C}_{3}$ carbonyl compounds, and likely not soluble enough to decrease the water activity of the sulfuric acid core, and, like the $\mathrm{C}_{8}$ to $\mathrm{C}_{10}$ compounds, are likely to form a coating on the surface of the aerosol. However, the freezing temperatures of these intermediate chain length aldehydes are apparently too low, due to the lower melting points and some supercooling effects, to induce a heterogeneous freezing mechanism. As a result, the sulfuric acid core determines the ice nucleation temperature in these aerosols.

Because the time scale for the previously described experiments was much too short to observe acid-catalyzed reactions, an alternative set of experiments was performed in which a bulk solution of sulfuric acid was reacted with butanal for an extended period of time ( $\sim 7$ days) before being atomized and used for ice nucleation experiments. Acidcatalyzed reaction products were verified using ${ }^{1} \mathrm{H}-\mathrm{NMR}$ analysis similar to that described by Garland et al. (2006). Although it was not possible to determine the organic composition of the aerosols in these experiments, the water to sulfate ratio was fortuitously similar to the previous experiments. Therefore, the ice nucleation results could be compared to the ice nucleation temperature of $-54^{\circ} \mathrm{C}$ for the base case of $15 \mathrm{wt} \%$ sulfuric acid. Interestingly, these butanal bulk-reacted aerosols nucleated ice at $-51^{\circ} \mathrm{C}$. This is $\sim 3^{\circ} \mathrm{C}$ warmer than the result observed for the gas addition of butanal, $\mathrm{C}_{4}$, to aqueous sulfuric acid aerosols, while only $\sim 1^{\circ} \mathrm{C}$ cooler than that observed for gaseous addition of octanal, $\mathrm{C}_{8}$, which would be expected to have similar physical properties to 2-ethyl-2-hexenal, the aldol condensation reaction product of butanal. While preliminary, these experiments seem to indicate that acid-catalyzed reactions can indeed result in a change in the mode of ice nucleation for the case of butanal and lead to an increase in ice nucleation temperature.

\section{Implications and conclusions}

Acid-catalyzed reactions could play an important role in determining which ice nucleation mode might be operative in mixed organic/inorganic aerosols in the atmosphere. In these reactions, shorter chain organic molecules react to create molecules of at least the sum of the carbon chain length. As can be see from Fig. 9, a doubling in carbon chain length from $\mathrm{C}_{4}$ to $\mathrm{C}_{8}$, increases melting temperature by $70^{\circ} \mathrm{C}$ and decreases solubility by a factor of 100 . From the interpretation of the present experiments, aqueous sulfuric acid aerosols exposed to butanal nucleated ice by a homogeneous mechanism, while octanal-exposed sulfuric acid aerosols nucleate ice via a heterogeneous mechanism. Therefore, acidcatalyzed reactions on sulfuric acid aerosols could play a role in transforming organic compounds from those that likely depress or have no effect on ice nucleation temperatures to those that actually elevate the ice nucleation temperatures 
through heterogeneous nucleation. However, if no reaction transforms the shorter carbon chain organic compounds to larger organic compounds, the solubility limit will likely not be reached for the shorter carbon chain, highly soluble organic species in the atmosphere (Marcolli et al., 2004).

The present work has shown that addition of organic compounds to $15 \mathrm{wt} \%$ sulfuric acid aerosol can lead to a depression, no change, or even an elevation in the ice nucleation temperature. It has been shown that the physical properties of the organic compounds, in particular the solubility and melting point, can be used to interpret the observed ice nucleation temperature. For example, very soluble organic compounds can decrease the water activity of atmospheric aerosols under non-equilibrium conditions (i.e. rapid cooling plumes; Kärcher and Koop, 2005), and lead to a decrease in ice nucleation temperatures. At some concentration, a solubility limit will be reached and a second organic phase will begin to form on the aqueous aerosol. If the freezing temperature of the organic phase is lower than that of the mixed aerosol core, then the organic phase is seen to have no effect on the ice nucleation temperatures. However based on this interpretation, if the freezing temperature of the organic phase is higher than that of the aerosol core, a heterogeneous nucleation mode can occur and higher ice nucleation temperatures will be observed. In general, longer chain organic compounds will induce heterogeneous ice nucleation due to their high melting temperatures. Therefore, knowing the chemical speciation of the organics present in upper tropospheric aerosols is valuable information when predicting their effects on ice nucleation in dilute sulfuric acid aerosols.

Acknowledgements. The authors would like to acknowledge A. Y. Zasetsky for access to the Mie scattering computer program. The authors also acknowledge M. E. Wise for helpful discussions. MJE acknowledges the American Chemical Society Petroleum Research Fund and the Mellon Foundation for sabbatical support. MRB acknowledges the EPA STAR fellowship program (FP-91654601) for financial support. The research described in this paper has been funded in part by the United States Environmental Protection Agency (EPA) under the Science to Achieve Results (STAR) Graduate Fellowship Program. EPA has not officially endorsed this publication and the views expressed herein may not reflect the views of the EPA. The authors also acknowledge DOE under grant no. DE-FG03-01ER63096 and NSF under grant no. ATM-0137261 for funding.

Edited by: J. Abbatt

\section{References}

Anthony, S. E., Tisdale, R. T., Disselkamp, R. S., and Tolbert, M. A.: FTIR studies of low temperature sulfuric acid aerosols, Geophys. Res. Lett., 22, 1105-1108, 1995.

Atkins, P.: Physical Chemistry, W.H. Freeman and Company, New York, 1997.
Bertram, A. K., Koop, T., Molina, L. T., and Molina, M. T.: Ice formation in $\left(\mathrm{NH}_{4}\right)_{2} \mathrm{SO}_{4}-\mathrm{H}_{2} \mathrm{O}$ Particles, J. Phys. Chem. A., 104, 584-588, 2000.

Bertram, A. K., Patterson, D. D., and Sloan, J. J.: Mechanisms and temperatures for the freezing of sulfuric acid aerosols measured by FTIR extinction spectroscopy, J. Phys. Chem., 100, 23762383, 1996.

Bohren, C. F. and Huffman, D. R.: Absorption and Scattering of Light by Small Particles, John Wiley \& Sons, New York, 1983.

Chen, Y., DeMott, P. J., Kreidenweis, S. M., Rogers, D. C., and Sherman, D. E.: Ice formation by sulfate and sulfuric acid aerosol particles under upper-tropospheric conditions, J. Atmos. Sci., 57, 3752-3766, 2000.

Cziczo, D. J. and Abbatt, J. P. D.: Ice nucleation in $\mathrm{NH}_{4} \mathrm{HSO}_{4}$, $\mathrm{NH}_{4} \mathrm{NO}_{3}$, and $\mathrm{H}_{2} \mathrm{SO}_{4}$ aqueous particles: Implications for cirrus cloud formation, Geophys. Res. Lett., 28, 963-966, 2001.

Cziczo, D. J., DeMott, P. J., Brooks, S. D., Prenni, A. J., Thomson, D. S., Baumgardner, D., Wilson, J. C., Kreidenweis, S. M., and Murphy, D. M.: Observations of organic species and atmospheric ice formation, Geophys. Res. Lett., 31, L12116, doi:10.1029/2004GL019822, 2004.

DeMott, P. J.: Laboratory studies of cirrus cloud processes, in: Cirrus, edited by: Lynch, D. K., Sassen, K., Starr, D. O. C., and Stephens, G., Oxford Univ. Press, 102-135, 2002.

DeMott, P. J., Cziczo, D. J., Prenni, A. J., Murphy, D. M., Kreidenweis, S. M., Thomson, D. S., Borys, R., and Rogers, D. C.: Measurements of the concentration and composition of nuclei for cirrus formation, Proc. Natl. Acad. Sci. USA., 100, $14655-$ $14660,2003$.

Fahey, D. W. and Schumann, U.: Aviation-produced aerosols and cloudiness, in: Aviation and the Global Atmosphere, edited by: Penner, J. E., Lister, D. H., Griggs, D. J., Dokken, D. J., and McFarland, M., Camgridge University Press, 373, 1999.

Garland, R. M., Elrod, M. J., Kincaid, K., Beaver, M. R., Jimenez, J. L., and Tolbert, M. A.: Acid-catalyzed reactions of hexanal on sulfuric acid particles: Identification of reaction products, Atmos. Environ., in press, 2006.

Grosjean, E., Grosjean, D., Fraser, M. P., and Cass, G. R.: Air quality model evaluation data for organics. $2 . \mathrm{C}_{1}-\mathrm{C}_{14}$ carbonyls in Los Angeles air, Environ. Sci. Technol., 30, 2687-2703, 1996.

Hazardous Substances Data Bank, National Library of Medicine, updated on 14 February 2003, http://toxnet.nlm.nih.gov/cgi-bin/ sis/htmlgen?HSDB, 2004.

Hung, H.-M., Malinowski, A., and Martin, S. T.: Ice nucleation kinetics of aerosols containing aqueous and solid ammonium sulfate particles, J. Phys. Chem. A, 106, 293-306, 2002.

Imamura, T. and Akiyoshi, H.: Uptake of actone into sulfuric acid solutions, Geophys. Res. Lett., 27, 1419-1422, 2000.

Iraci, L. T. and Tolbert, M. A.: Heterogeneous interaction of formaldehyde with cold sulfuric acid: Implications for the upper troposphere and lower stratosphere, J. Geophys. Res., 102, 16099-16 107, 1997.

Jang, M., Czoschke, N. M., Lee, S., and Kamens, R. M.: Heterogeneous atmospheric aerosol production by acid-catalyzed particlephase reactions, 298, 814-817, 2002.

Kane, S. M., Timonen, R. S., and Leu, M.-T.: Heterogeneous chemistry of acetone in sulfuric acid solutions: Implications for the Upper Troposphere, J. Phys. Chem. A, 103, 9259-9265, 1999. 
Kärcher, B. and Koop, T.: The role of organic aerosols in homogeneous ice formation, Atmos. Chem. Phys., 5, 703-714, 2005, http://www.atmos-chem-phys.net/5/703/2005/.

Klassen, J. K., Lynton, J., Golden, D. M., and Williams, L. R.: Solubility of acetone in low-temperature (210-240 K) sulfuric acid solutions, J. Geophys. Res., 104, 26355-26361, 1999.

Koop, T., Luo, B., Tsias, A., and Peter, T.: Water activity as the determinant for homogeneous ice nucleation in aqueous solutions, 406, 611-614, 2000.

Koop, T., Ng, H. P., Molina, L. T., and Molina, M. J.: A new optical technique to study aerosol phase transitions: The nucleation of ice from $\mathrm{H}_{2} \mathrm{SO}_{4}$ aerosols, J. Phys. Chem. A, 102, 8924-8931, 1998.

Liggio, J., Li, S. M., and McLaren, R.: Heterogeneous reactions of glyoxal on particulate matter: identification of acetals and sulfate esters, Environ. Sci. Technol., 39, 1532-1541, 2005.

Marcolli, C, Luo, B., and Peter, T.: Mixing of the organic aerosol fractions: Liquids as the thermodynamically stable phase, J. Phys. Chem. A, 108, 2216-2224, 2004.

Michelsen, R. R., Ashbourn, S. F. M., and Iraci, L. T.: Dissolution, speciation, and reaction of acetaldehyde in cold sulfuric acid, J. Geophys. Res., 109, D23205, doi:10.1029/2004JD005041, 2004.

Murphy, D. M., Thomson, D. S., and Mahoney, M. J.: In situ measurements of organics, meteoritic material, mercury, and other elements in aerosols at 5 to 19 kilometers, 282, 1664-1669, 1998.

Myhre, C. E. L., Christensen, D. H., Nicolaisen, F. M., and Nielsen, C. J.: Spectroscopic study of aqueous $\mathrm{H}_{2} \mathrm{SO}_{4}$ at different temperatures and compositions: variations in dissociation and optical properties, J. Phys. Chem. A, 107, 1979-1991, 2003.

Nozière, B. and Esteve, W.: Organic reactions increasing the absorption index of atmospheric sulfuric acid aerosols, Geophys. Res. Lett., 32, L03812, doi:10.1029/2004GL021942, 2005.
Nozière, B. and Riemer, D. D.: The chemical processing of gas-phase carbonyl compounds by sulfuric acid aerosols: 2,4pentanedione, Atmos. Environ., 37, 841-851, 2003.

Prenni, A. J., DeMott, P. J., Kreidenweis, S. M., Sherman, D. E., Russell, L. M., and Ming, Y.: The effects of low molecular weight dicarboxylic acids on cloud formation, J. Phys. Chem. A, 105, 11240-11 248, 2001a.

Prenni, A. J., Wise, M. E., Brooks, S. D., and Tolbert, M. A.: Ice nucleation in sulfuric acid and ammonium sulfate particles, J. Geophys. Res., 106, 3037-3044, 2001 b.

Rasmussen. D. H. and MacKenzie, A. P.: Effect of solute on icesolution interfacial free energy; calculation from measured homogeneous nucleation temperatures, in: Water Structure at the Water-Polymer Interface, edited by: Jellinek, H. H. G., Plenum Press, 126-145, 1972.

Thermodynamics Source Database, National Institute of Standards and Technology, updated on 2005 June, http://webbook.nist.gov, 2005.

Wise, M. E., Garland, R. M., and Tolbert, M. A.: Ice nucleation in internally mixed ammonium sulfate/dicarboxylic acid particles, J. Geophys. Res., 109, D19203, doi:10.1029/2003JD004313, 2004.

Zasetsky, A. Y., Khalizov, A. F., and Sloan, J. J.: Characterization of atmospheric aerosols from infrared measurements: simulations, testing, and applications, Appl. Opt., 43, 5503-5511, 2004.

Zhao, J., Levitt, N. P., and Zhang, R.: Heterogeneous chemistry of octanal and 2,4-hexadienal with sulfuric acid, Geophys. Res. Lett., 32, L09802, doi:10.1029/2004GL022200, 2005. 